\title{
Functional and Oncological Outcomes of Multidisciplinary Management of Ewing's Sarcoma of Clavicle: A Single-Center Experience
}

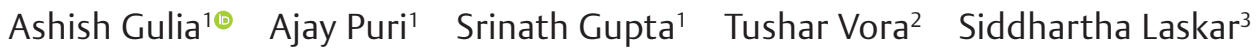

${ }^{1}$ Department of Surgical Oncology, Tata Memorial Hospital, and Homi Bhabha National Institute (HBNI), Mumbai, Maharashtra, India; ${ }^{2}$ Department of Medical Oncology, Tata Memorial Hospital, and Homi Bhabha National Institute (HBNI), Mumbai, Maharashtra, India; ${ }^{3}$ Department of Radiation Oncology, Tata Memorial Hospital, and Homi Bhabha National Institute (HBNI), Mumbai, Maharashtra, India

\section{South Asian J Cancer 2021;10:138-143.}

Address for correspondence Dr. Ashish Gulia, MS (Ortho), Mch, Bone and Soft Tissue Services,Department of Surgical Oncology, 93, Main building, Tata Memorial Hospital, and Homi Bhabha National Institute (HBNI), Mumbai 400012, India (e-mail: aashishgulia@gmail.com).

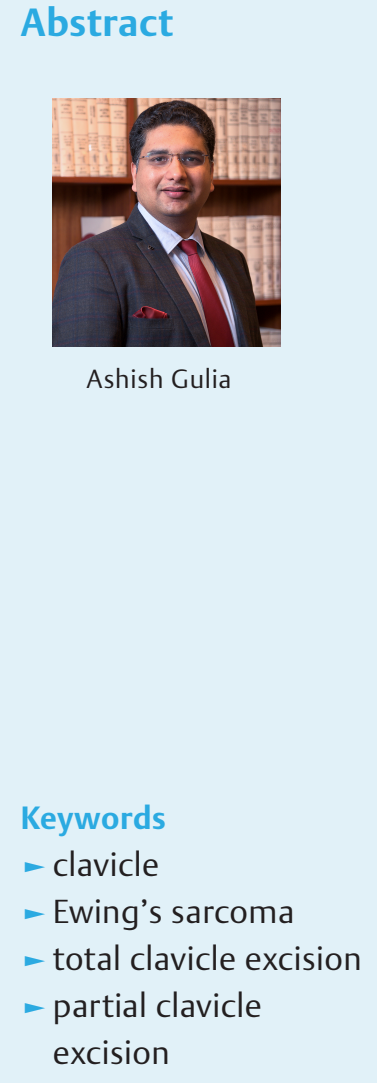

Objectives Ewing's sarcoma is best treated using a multidisciplinary approach. We discuss the functional and oncological outcomes of clavicular Ewing's sarcoma which has been sparsely reported in literature.

Materials and Methods We retrospectively evaluated patients who underwent resections for Ewing's sarcoma of clavicle from January 2002 to December 2017. The study end points were locoregional recurrence free survival (LRFS), disease-free survival (DFS), and overall survival (OS) at 3 and 5 years, and functional outcomes measured by Musculoskeletal Tumor Society (MSTS) scores.

Statistical Analysis The LRFS, DFS, and OS were calculated and analyzed using the Kaplan-Meier method and log-rank test.

Results Data of 21 patients (male: 12, female: 9) was analyzed with a mean age [range] of 15.3 [6-40] years. Total clavicle excision was done in $62 \%$ (13 of 21) while 38\% ( $n=8)$ had partial resections. Radiotherapy was administered in 15 patients (71.5\%). At a median follow-up of 42 months (range: 7-198), data of 20 patients was available for follow-up. Ten patients died (due to disease: nine, other reasons: One), eight are disease free and alive, one had metastasectomy on recurrence and is disease free and, one patient is alive with disease and on palliative chemotherapy. The LRFS, DFS, and OS were 95, 59, 65\% and 95, 47, 59\% at 3 and 5 years, respectively. The functional evaluation done for nine patients who are free of disease showed a mean MSTS score of 29 (range: 27-30; total clavicle excision: 28.5, partial clavicle excision: 29.5). Conclusion Patients with Ewing's sarcoma of the clavicle who underwent resection without reconstruction have acceptable local control rates and excellent functional outcomes.
DOI https://doi.org/10.1055/s-0041-1731901 ISSN 2278-330X

How to cite this article: Gulia A, Puri A, Gupta S, et al. Functional and Oncological Outcomes of Multidisciplinary Management of Ewing's Sarcoma of Clavicle: A Single-Center Experience South Asian J Cancer 2021;10(3):138-143. (c) 2021. MedIntel Services Pvt Ltd.

This is an open access article published by Thieme under the terms of the Creative Commons Attribution-NonDerivative-NonCommercial-License, permitting copying and reproduction so long as the original work is given appropriate credit. Contents may not be used for commercial purposes, or adapted, remixed, transformed or built upon. (https://creativecommons.org/licenses/by-nc-nd/4.0/).

Thieme Medical and Scientific Publishers Private Ltd A-12, Second Floor, Sector -2, NOIDA -201301, India 


\section{Introduction}

Primary clavicle tumors are uncommon and account for $<1 \%$ of primary bone tumors. Limited case reports or case series are currently available that provide information on these tumors. ${ }^{1,2}$ The majority of primary clavicle tumors are malignant $^{3,4}$ and surgical treatment entails partial or total clavicle excision based on the disease extent. ${ }^{5}$

Approximately $1.4 \%$ of all cases of Ewing's sarcoma occur in the clavicle. ${ }^{6}$ While chemotherapy is mandatory for cure, surgical excision is the preferred modality for local control in Ewing's sarcoma. Radiotherapy in addition to surgery or radiotherapy alone is an acceptable option.

We report here a single institution study of Ewing's sarcoma of clavicle treated with surgical excision. We evaluated the functional and oncology outcomes and compared outcomes between total and partial clavicle excisions.

\section{Materials and Methods}

\section{Patients}

This retrospective analysis included data from our prospectively maintained database. Cases $(N=21)$ of histologically proven Ewing's sarcoma of clavicle who underwent surgical excision (partial or total clavicle excision) between January 2002 and December 2017 were included. The mean age of the patients was 15.3 (range: 6-40) years and the majority $(58 \%, 12 / 21)$ were males. - Table 1 presents the baseline demographics and characteristics of the patients. Baseline imaging was done in the form of a plain radiograph and magnetic resonance imaging of the shoulder region screening the entire clavicle.

Histopathology was confirmed with a core needle biopsy or histopathology review of slides/blocks if a biopsy was done elsewhere. Staging investigations included computerized tomography (CT) of the chest and either a fluorodeoxyglucose-positron emission tomography (FDG-PET) scan or a combination of a bone scan and a bone marrow aspiration biopsy.

Table 1 Patient demographics and baseline characteristics

\begin{tabular}{|c|c|}
\hline Parameters & $N=21$ \\
\hline Age (years), mean, range & $16(6-40)$ \\
\hline \multicolumn{2}{|l|}{ Sex, $n(\%)$} \\
\hline Male & $12(58 \%)$ \\
\hline Female & $9(42 \%)$ \\
\hline \multicolumn{2}{|l|}{ Details of surgery, $n$ (\%) } \\
\hline Total clavicle excision & $13(62 \%)$ \\
\hline Partial clavicle excision & $8(38 \%)$ \\
\hline \multicolumn{2}{|l|}{ Adjuvant treatment, $n(\%)$} \\
\hline $\begin{array}{l}\text { Chemotherapy plus } \\
\text { radiotherapy }\end{array}$ & $15(71.5 \%)$ \\
\hline Chemotherapy only & $6(28.5 \%)$ \\
\hline
\end{tabular}

Abbreviations: $n$, number of patients; SD, standard deviation.
The final treatment plan was decided in multidisciplinary joint clinics (MDJC). Patients with disseminated disease were not offered surgical excision and were treated with palliative intent. These patients are not included in this analysis. Three (14\%) of the 21 patients in this series were metastatic at presentation (two-pulmonary and one-lymph nodes). All the patients included in this study were treated with curative intent. Two (10\%) of the 21 patients had a pathological fracture through the clavicle at presentation.

\section{Chemotherapy}

Patients were administered chemotherapy as per standard institute protocol. The protocol included two courses of VIE couplet (vincristine, ifosfamide, and etoposide) followed by two courses of VAC couplet (vincristine, doxorubicin, and cyclophosphamide) administered every 3 weeks. Maintenance therapy after treatment of the primary tumor included 10 courses of alternating VAC and VIE couplets, with actinomycin $\mathrm{D}$ substituted for doxorubicin after a total dose of $360 \mathrm{mg} / \mathrm{m}^{2}$. Vincristine was administered weekly throughout between the chemotherapy pulses.

\section{Pathology}

All resected specimens were evaluated for margin status and percentage necrosis. ${ }^{7}$ Based on the percentage necrosis, patients were divided into good necrosis (necrosis $>90 \%$ ) and poor necrosis (necrosis $<90 \%$ ).

\section{Radiotherapy}

Radiotherapy was usually recommended for those with poor response to chemotherapy, in patients with a large soft tissue component at presentation and those who had an open biopsy or pathological fracture. The target volume for radiation therapy included the pretreatment extent of disease with appropriate margins. External beam radiotherapy was delivered postoperatively to a dose of $45 \mathrm{~Gy} / 25 \# / 5$ weeks with conformal portals.

\section{Follow-up}

Patients were followed-up every 6 months for the first 5 years and annually till 10 years. Chest and local radiographs were done as part of imaging. Based on clinical and radiological suspicion of local or distant recurrence, additional studies including biopsy/fine needle aspiration cytology were done. Functional analysis using Musculoskeletal Tumor Society (MSTS) scoring system was done at the time of the last follow-up. The MSTS for the upper limb is based on the analysis of six factors, i.e., pain, function, emotional acceptance, hand positioning, manual dexterity, and lifting ability. For each of the six factors, values of 0 to 5 were assigned based on established criteria. The result is expressed as a sum total with a maximum score of 30.8

\section{Study Assessments}

A detailed patient history in addition to gender, symptoms on presentation, histology, treatment details in the form of surgery (partial/total clavicle excision), chemotherapy, radiotherapy, local and distant recurrences, complications, 
current status, and the MSTS score were recorded and compared. The study end points included the evaluation of disease outcomes (locoregional recurrence free survival [LRFS], disease-free survival [DFS], overall survival [OS] at 3 and 5 years) and functional MSTS scores.

\section{Statistical Analysis}

Demographic and baseline characteristics were summarized using descriptive statistics. Categorical variables were summarized with frequency and percentage. Continuous variables were summarized with count, mean, standard deviation, median, minimum and maximum. Survival analysis was performed to measure lifetime or the length of time until the occurrence of an event (disease recurrence in cases of LRFS, disease progression in case of DFS, and death in case of OS). Survival data was analyzed using SPSS version 21 to measure the duration of time until a specified event occurs. LRFS, DFS, and OS were calculated and analyzed using the Kaplan-Meier method and log-rank test.

\section{Results}

\section{Surgery Details}

Of 21 patients in this study, $60 \%(n=13)$ patients had a total clavicle excision and $40 \%(n=8)$ had a partial clavicle excision. A margin of $2 \mathrm{~cm}$ beyond disease or disarticulation of the adjacent joint, if necessary, was considered adequate oncologic resection while performing a partial clavicle excision. ${ }^{9}$ No reconstruction was done in any case. One patient had an intraoperative rent in the subclavian vein which was repaired. Wound necrosis was observed in one patient which was managed conservatively. None of the patients had any permanent sequelae of complications. Margins were negative in all cases.

\section{Neoadjuvant Therapy}

All patients received neoadjuvant chemotherapy followed by surgery between 10 and 12 weeks after starting chemotherapy. Fourteen patients (67\%) had good response while six (28\%) patients had a poor response to chemotherapy; details were not available in one patient. After MDJC discussion, radiotherapy was administered in 15 (71\%) cases (1-preoperative and 14-postoperative) in view of poor necrosis, large disease volume at presentation, pathological fracture, or prior intervention in form of open biopsy elsewhere. Of the two patients with a pathological fracture, one received postoperative radiotherapy while the other patient was 11 years old with $100 \%$ necrosis for whom MDJC decided not to administer radiotherapy. The patient is currently disease free after 116 months. All the six patients who did not receive radiotherapy had good necrosis and negative surgical margins of resection.

\section{Survival}

Of 21 patients, 20 had complete follow-up details. 10 patients died (nine due to disease and one due to other reasons). Eight patients remain disease free and alive. Isolated distance recurrence was observed in 10 patients of which two had lung metastasis at presentation and one had nodal disease.
Only two out of these 10 patients are alive, one who underwent metastasectomy and is currently free of disease, and another patient who is on palliative treatment (had nodal metastasis at presentation).

One local recurrence (5\%) occurred at 12 months after completion of the treatment. The local recurrence was resected again but eventually the patient died due to distant metastasis.

The median follow-up of the entire cohort was 42 months (range: 7-198 months). In survivors, the median follow-up was 92 months (range: 30-198 months). The LRFS, DFS, and OS were $95,59,65 \%$ at 3 years, and $95,47,59 \%$ at 5 years, respectively. Poor necrosis $(<90 \%)$ had a significant impact on OS $(p=0.024)$. The administration of radiotherapy did not have a significant impact on LRFS, DFS, or OS ( - Table 2 ).

\section{Shoulder Function}

The MSTS was available for nine patients who are currently free of disease. The median MSTS score was 29 (range: 27-30). The MSTS score after total clavicle excision (-Fig. 1) was $28.5(n=5)$ compared with $29.5(n=4)$ for those who underwent partial clavicle excision ( - Fig. 2$)(p=0.125)$.

\section{Discussion}

Primary clavicle tumors are rare accounting for $<1 \%$ of bone tumors. In an analysis by Klein, clavicle tumors were only $0.45 \%$ of more than 13,000 primary bone tumors. ${ }^{10,11}$ The most common histologic diagnosis of clavicle tumors are myeloma, Ewing's sarcoma, and osteosarcoma. ${ }^{12}$ As in other primary bone sarcomas, in the clavicle too, adequate resection of the bone (partial or total clavicle excision) is the procedure of choice for best local control. ${ }^{13}$

In a study published by Mayilvahan of six cases of Ewing's sarcoma of the clavicle, two died post-surgery due to disease. ${ }^{11}$ Of the five cases published by Martin et al, one patient died of metastases post-surgery. ${ }^{14}$ Our series of 21 cases with much larger numbers had a LRFS, DFS, and OS of $95,59,65 \%$ ( - Table 4 ) at 3 years and $95,47,59 \%$ at 5 years, respectively ( $\sim$ Table 3 ).

Even Ewing's sarcoma with limited metastasis at presentation has a poor prognosis. Our series had $14 \%$ of patients (three of 21) with limited metastasis at presentation who were treated with curative intent. Those who were metastatic at presentation $(n=3)$ had a survival of $33 \%$ at 5 years as against nonmetastatic patients who had 64\% OS at 5 years. Apart from these three, those who developed metastases (seven patients) subsequently too had poor survival. Of these 10 patients, only two patients are currently alive

Table 2 Response to chemotherapy and survival

\begin{tabular}{|l|l|l|l|}
\hline & 5-y LRFS & 5-y DFS & 5-y OS \\
\hline Good necrosis (>90\%) & $96 \%$ & $51 \%$ & $66 \%$ \\
\hline Poor necrosis (<90\%) & $100 \%$ & $25 \%$ & $33 \%$ \\
\hline$p$-Value & 0.535 & 0.182 & 0.024 \\
\hline
\end{tabular}

Abbreviations: DFS, disease-free survival; LRFS, loco-regional free survival; OS, overall survival. 


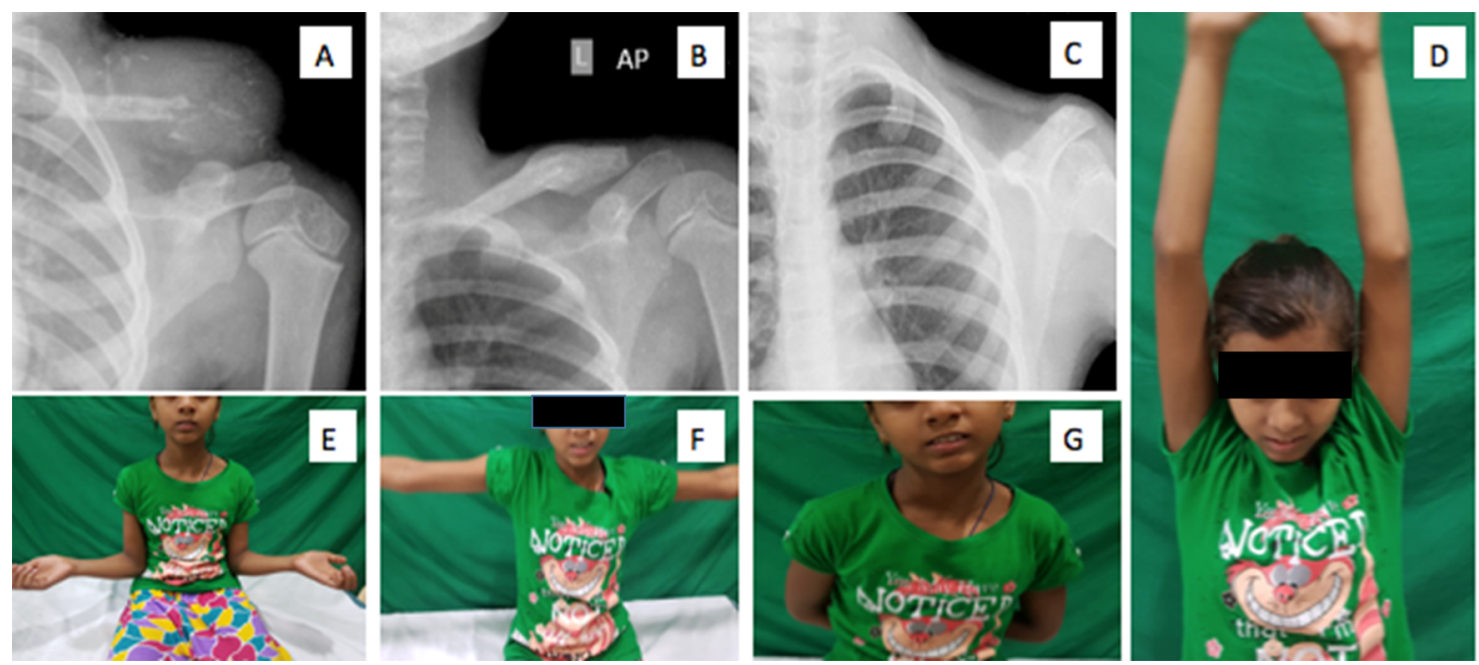

Fig. 1 (A) Radiograph at presentation, showing destructive lytic lesion of left clavicle with large soft tissue component in a 6-year-old female diagnosed with Ewing sarcoma. (B) Post-chemotherapy radiographs showing good response to chemotherapy (reduction in soft tissue component and union of pathological fracture). (C) Four-year follow-up radiograph post-total clavicle excision. (D-G) Excellent functional outcome.

(one is disease free 1 year after metastasectomy and the other patient is on palliative chemotherapy). Our survival of $64 \%$ (nonmetastatic patients) is comparable to other studies by Pradhan et $a l,{ }^{15}$ who reported a survival of $72 \%$ for peripheral lesions and $78 \%$ for nonmetastatic lesions, and Nesbit et $\mathrm{al}^{16}{ }^{16}$ who reported survival in the range of 56 to $79 \%$ (nonpelvis and nonmetastatic).

Poor response to chemotherapy is one of the strongest prognostic factors in Ewing's sarcoma. ${ }^{17}$ Similarly in our series too, the 5 -year OS in $28 \%$ (six out of 21 ) patients with poor response to chemotherapy was 33\% as against the $66 \%$ OS in the good responders.

The decision to offer radiotherapy as an adjunct to surgery was decided on a case-by-case basis as detailed earlier after discussion in a multidisciplinary clinic. Though it can be argued that there could be an element of subjective clinical bias in the decision making, consistency was maintained as the treating team was the same for all cases. There was no statistical significance in local recurrence and survival based on the addition of radiotherapy. Given that many patients of Ewing's sarcoma are in the pediatric age group, our approach in using radiotherapy selectively appears justified. The apparently better DFS and OS in the group that did not receive radiotherapy is possibly because of the selection bias; cases that received radiotherapy were judged by the multidisciplinary team to be in a higher risk group compared with those that did not.

The clavicle being in close vicinity to major anatomical structures can be challenging to excise especially in cases with a large soft tissue mass. There are differing opinions regarding the need to reconstruct the clavicle after excision. ${ }^{1}$ While several reports have described no abnormality in shoulder function after clavicle excision, shoulder dysfunction, dyskinesis of the scapula, and damage to the shoulder joint have been reported. ${ }^{1,18}$ Though reconstruction using allogeneic and autologous bone, bone cement, and a plate-cement complex has been done to mitigate post-clavicle excision complications, they in turn have resulted in increased chances of infection, prosthesis loosening, persistent pain, and symptomatic nonunion. ${ }^{1,19}$

In our series where no reconstruction after excision was attempted a surgical complication in the form of wound necrosis was observed in only one patient. This too settled with conservative management without the need for further surgical intervention.

The MSTS score is a well-accepted method to study the functional evaluation of patients with extremity tumors. ${ }^{8}$ Our patients had a mean MSTS score of 29 (range: 27-30). The functional scores were similar for both the groups (total clavicle excision: 28.5, partial clavicle excision: 29.5). This is in concurrence with the results reported by Kapoor et $\mathrm{al}^{3}{ }^{3}$ where both total and partial clavicle excision without reconstruction were not associated with a clinically significant loss of function based on the MSTS score. ${ }^{3}$ Wessel and Schaap, ${ }^{20}$ in a series of six patients (two malignant tumors) who underwent total clavicle excision reported that resection of the entire clavicle did not disturb the motion of the shoulder. ${ }^{20}$ In a study by Natarajan et al, ${ }^{11}$ the functional outcomes after clavicle excision evaluated in 12 patients (Ewing's sarcoma: 6) were excellent in five cases and good in seven cases. The strength of abduction and flexion though limited in two patients did not impinge on the overall functional outcomes ( - Table 4 ). ${ }^{11}$

Our study suffers from the limitations inherent to any retrospective study. The numbers though small are inevitable

Table 3 Radiotherapy and survival

\begin{tabular}{|l|l|l|l|}
\hline Radiotherapy & 5-y LRFS & 5-y DFS & 5-y OS \\
\hline Yes & $100 \%$ & $32 \%$ & $49 \%$ \\
\hline No & $83 \%$ & $83 \%$ & $83 \%$ \\
\hline$p$-Value & 0.141 & 0.065 & 0.110 \\
\hline
\end{tabular}

Abbreviations: DFS, disease-free survival; LRFS, loco-regional free survival; OS, overall survival; RT, radiotherapy. 

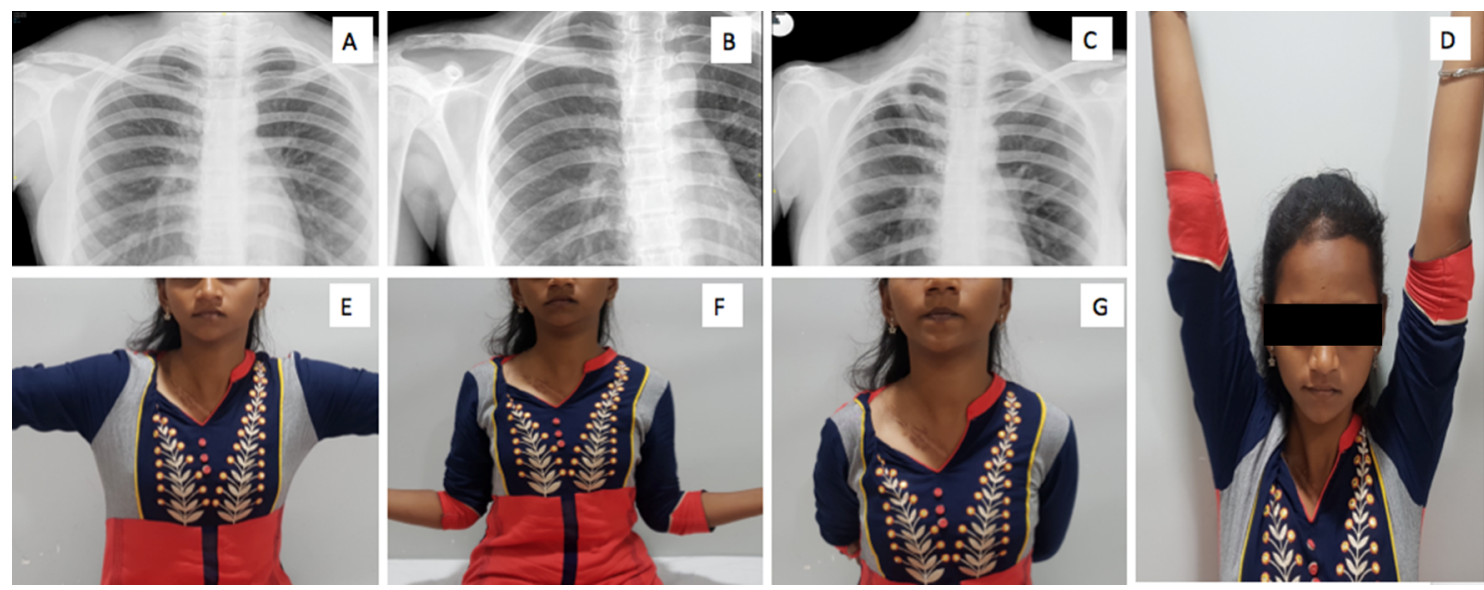

Fig. 2 (A) Radiograph at presentation, showing lytic lesion of the lateral end of right clavicle in a 16-year-old female diagnosed with Ewing sarcoma. (B) Post-chemotherapy radiographs showing good response to chemotherapy. (C) A 6-year follow-up radiograph post partial clavicle excision. (D-G) Excellent functional outcome.

Table 4 Comparison with published literature related to Ewing's sarcoma of clavicle

\begin{tabular}{|c|c|c|c|c|c|c|c|c|c|}
\hline Author & $\begin{array}{l}\text { Total } \\
\text { cases }\end{array}$ & $\begin{array}{l}\text { Ewing's } \\
\text { sarcoma of } \\
\text { clavicle }\end{array}$ & $\begin{array}{l}\text { Follow-up } \\
\text { (months) } \\
\text { (median) }\end{array}$ & $\begin{array}{l}\text { Alive/Dead } \\
\text { (Only } \\
\text { Ewing's } \\
\text { sarcoma) }\end{array}$ & $\begin{array}{l}\text { Total/ } \\
\text { Partial } \\
\text { clavicle } \\
\text { excision }\end{array}$ & $\begin{array}{l}\text { Mean functional } \\
\text { outcome } \\
\text { (number of } \\
\text { cases with no } \\
\text { reconstruction) }\end{array}$ & $\begin{array}{l}\text { Mean functional } \\
\text { outcome (number } \\
\text { of cases with } \\
\text { reconstruction) }\end{array}$ & $\begin{array}{l}5-y \\
\text { LRFS }\end{array}$ & $\begin{array}{l}5-y \\
0 S\end{array}$ \\
\hline Natarajan et al ${ }^{11}$ & 12 & 6 & 48 & $4 / 2$ & $7 / 5$ & $\begin{array}{l}\text { 5-Excellent } \\
\text { 7-Good (12) } \\
\text { (MSTS) }\end{array}$ & NA & NA & NA \\
\hline Li et al ${ }^{12}$ & 11 & 3 & 38 & $3 / 0$ & $5 / 6$ & $\begin{array}{l}27.5(5) \\
\text { (MSTS) }\end{array}$ & $\begin{array}{l}28.8(6) \\
\text { (MSTS) }\end{array}$ & NA & NA \\
\hline $\begin{array}{l}\text { Rodriguez } \\
\text { Martin et al }{ }^{14}\end{array}$ & 5 & 5 & 12 & $4 / 1$ & $1 / 4$ & $\begin{array}{l}93.5(2) \\
\text { (Constant shoulder } \\
\text { score) }\end{array}$ & $\begin{array}{l}77.5(2) \\
\text { (Constant shoulder } \\
\text { score) }\end{array}$ & NA & NA \\
\hline Our study & 21 & 21 & 42 & $10 / 10$ & $13 / 8$ & $\begin{array}{l}29(9) \\
\text { (MSTS) }\end{array}$ & NA & $95 \%$ & $59 \%$ \\
\hline
\end{tabular}

Abbreviations: LRFS, loco-regional free survival; MSTS, Musculoskeletal Tumor Society; OS, overall survival; RT, radiotherapy.

given the rarity of the site and the pathology. To the best of our knowledge this is the largest single institute study of Ewing's sarcoma in English literature.

\section{Conclusion}

Surgical resection (partial/total clavicle excision) without reconstruction as a part of multimodality treatment offers acceptable functional and oncological outcomes in primary Ewing's sarcoma of the clavicle and the oncologic outcomes are similar to that of Ewing's sarcoma at other skeletal sites.

\section{Data Availability Statement}

The data that support the findings of this study are available from the corresponding author upon reasonable request.

\section{Author Contributions}

All author equally participated in study design, data collection, data interpretation, and writing/review of the manuscript. All authors substantially contributed to the interpretation of data, critical revision of manuscript, and consented to the final version of the case report. All authors meet ICMJE criteria and all those who fulfilled those criteria are listed as authors. All named authors meet the International Committee of Medical Journal Editors (ICMJE) criteria for authorship for this article, take responsibility for the integrity of the work as a whole, and have given their approval for this version to be published.

\section{Ethics Statement}

This is a retrospective study of patients with Ewing's sarcoma of clavicle performed through the evaluation of patient's case records, and hence, Ethics Committee approval was not required.

\section{Funding}

None.

\section{Conflict of Interest}

None declared. 


\section{References}

1 Chen Y, Yu X, Huang W, Wang B. Is clavicular reconstruction imperative for total and subtotal claviculectomy? A systematic review. J Shoulder Elbow Surg 2018;27(5):e141-e148

2 Ren K, Wu S, Shi X, Zhao J, Liu X. Primary clavicle tumors and tumorous lesions: a review of 206 cases in East Asia. Arch Orthop Trauma Surg 2012;132(6):883-889

3 Kapoor S, Tiwari A, Kapoor S. Primary tumours and tumorous lesions of clavicle. Int Orthop 2008;32(6):829-834

4 Khatri K, Singh J, Kalia A, Dahuja A. Giant cell tumour of clavicle: occurrence of a common tumour in a rare location. Int J Surg Case Rep 2016;29:51-55

5 Li Z, Ye Z, Zhang M. Functional and oncological outcomes after total claviculectomy for primary malignancy. Acta Orthop Belg 2012;78(2):170-174

6 Priemel MH, Stiel N, Zustin J, Luebke AM, Schlickewei C, Spiro AS. Bone tumours of the clavicle: histopathological, anatomical and epidemiological analysis of 113 cases. J Bone Oncol 2019;16:100229

7 Sabanathan S, Shah R, Mearns AJ. Surgical treatment of primary malignant chest wall tumours. Eur J Cardiothorac Surg 1997;11(6):1011-1016

8 Enneking WF, Dunham W, Gebhardt MC, Malawar M, Pritchard DJ. A system for the functional evaluation of reconstructive procedures after surgical treatment of tumors of the musculoskeletal system. Clin Orthop Relat Res 1993;(286):241-246

9 Gulia A, Puri A, Subi TS, Gupta SM, Juvekar SL, Rekhi B. Comparison of MRI and histopathology with regard to intramedullary extent of disease in bone sarcomas. Sarcoma 2019;2019:7385470
10 Klein MJ, Lusskin R, Becker MH, Antopol SC. Osteoid osteoma of the clavicle. Clin Orthop Relat Res 1979;(143):162-164

11 Natarajan M, Meller I, Malawer MM. Claviculectomy for bone tumors. Indian J Orthop 2006;40:115-118

12 Li J, Wang Z, Fu J, Shi L, Pei G, Guo Z. Surgical treatment of clavicular malignancies. J Shoulder Elbow Surg 2011;20(2):295-300

13 Turra S, Gigante C. Primary clavicular localisation of Ewing's tumour treated by total cleidectomy. Case report and review of the literature. Ital J Orthop Traumatol 1988;14(3):389-393

14 Rodriguez Martin J, Pretell Mazzini J, Viña Fernandez R, Marti Ciruelos R, Curto de la Mano A. Ewing sarcoma of clavicle in children: report of 5 cases. J Pediatr Hematol Oncol 2009;31(11):820-824

15 Pradhan A, Grimer RJ, Spooner D, et al. Oncological outcomes of patients with Ewing's sarcoma: is there a difference between skeletal and extra-skeletal Ewing's sarcoma? J Bone Joint Surg Br 2011;93(4):531-536

16 Nesbit ME Jr, Gehan EA, Burgert EO Jr, et al. Multimodal therapy for the management of primary, nonmetastatic Ewing's sarcoma of bone: a long-term follow-up of the First Intergroup study. J Clin Oncol 1990;8(10):1664-1674

17 Jürgens $\mathrm{H}$, Exner $\mathrm{U}$, Gadner $\mathrm{H}$, et al. Multidisciplinary treatment of primary Ewing's sarcoma of bone. A 6-year experience of a European Cooperative Trial. Cancer 1988;61(1):23-32

18 Wood VE. The results of total claviculectomy. Clin Orthop Relat Res 1986;(207):186-190

19 Liu Y, Huang X-Y, Feng W-Y, et al. Analysis of the clinical efficacy of tumor resection methods used in 20 patients with clavicular tumor. World J Surg Oncol 2019;17(1):106

20 Wessel RN, Schaap GR. Outcome of total claviculectomy in six cases. J Shoulder Elbow Surg 2007;16(3):312-315

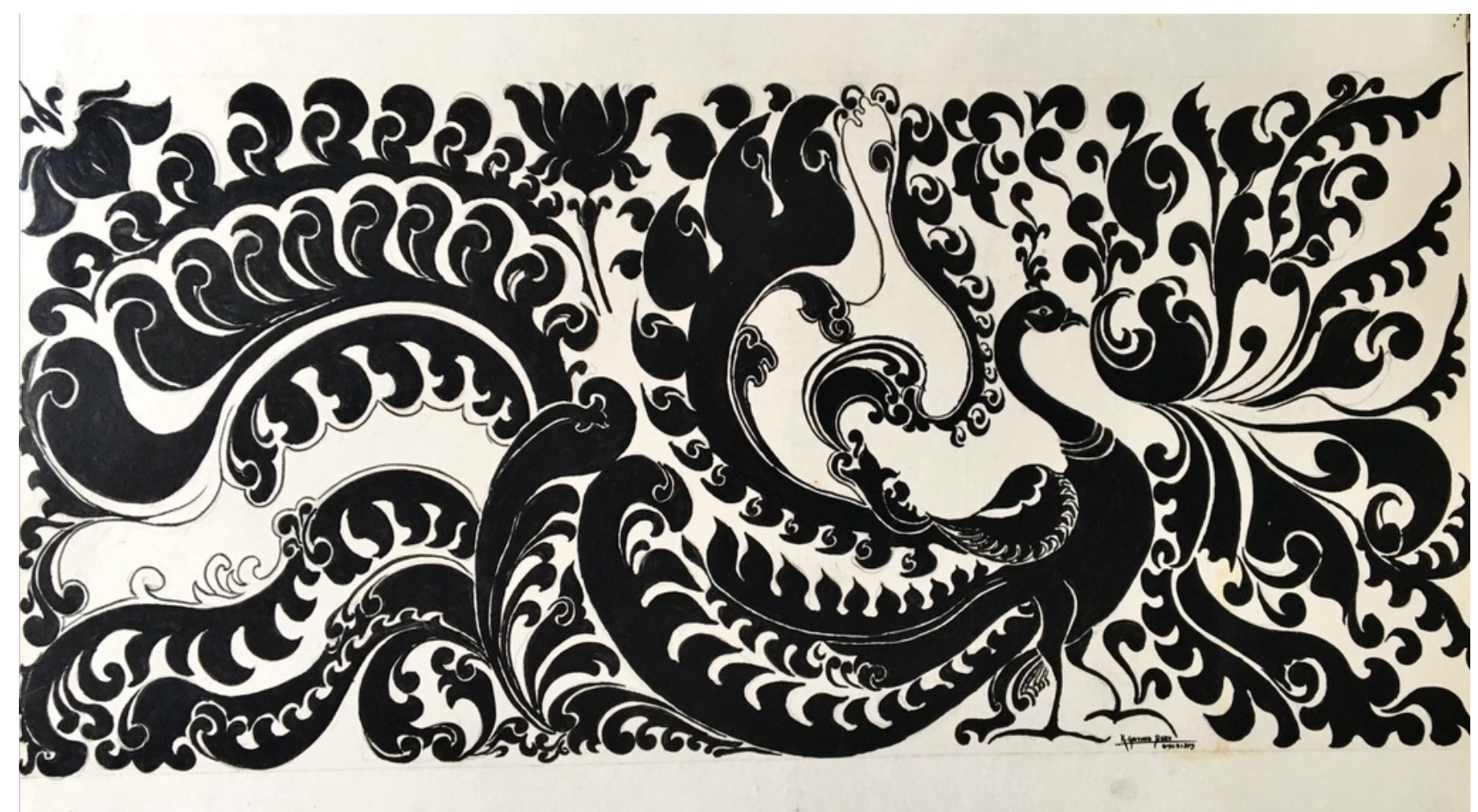

By Dr Govind Babu, President ISMPO and Senior Medical Oncologist 